\title{
French future: Exploring the future ratification hypothesis
}

\author{
AlDA MARI \\ Institut Jean Nicod (CNRS/ENS/EHESS) \\ Appeared in Journal of French Language Studies, 2015. \\ Pre-final draft.
}

ABSTRACT

The paper proposes a unified account of the systematic polysemy of French future (FUT) that does not uniquely rely on Aktionsart. It explains the predominant preference for the temporal interpretation of FUT, appealing to the 'future ratification hypothesis'. This is a felicity condition that can be satisfied to different degrees and among competing interpretations the one that satisfies it to the highest degree is preferred. The paper also shows that FUT does not convey uncertainty at utterance time $\left(t_{u}\right)$, and can be used when the attitude holder knows at $t_{u}$ that the embedded proposition is true.

\section{INTRODUCTION}

Future $^{1}$ sentences across languages are in many ways ambiguous. As far as we are aware, the temporal interpretation is the one shared by all languages. In this interpretation, the time of the event described in the sentence is forward-shifted with respect to the time of utterance $\left(t_{u}\right)$.

\footnotetext{
${ }^{1}$ Parts of the material in this paper have been presented at the 'Déterminants et inférences' and 'How do we know what happens?' workshops in Paris in 2013, as well as at the Chronos conference in Pisa, in 2014. We thank for their helpful discussion, Anastasia Giannakidou, Francis Corblin, Louis de Saussure, Claire Beyssade, Pascal Amsili, Lucia Tovena, Christian Retoré, Patrick Caudal, Guillaume Thomas, Vincent Homer, and Laura Baranzini. We are also grateful to the three anonymous reviewers and the associate editor for their remarks and comments. This research was funded by ANR-10-LABX-0087 IEC and ANR-10-IDEX-0001-02 PSL. This paper was written during my stay at the University of Chicago in 2014-2015. We also gratefully thank the CNRS-SMI 2015.
} 
(1.a) John will arrive at 4pm. (English)

(1.b) Gianni arriverà alle 4. (Italian)

John arrive.3SG.FUT at 4.

The repertoire of uses of future expressions (FUT from now on), however, varies widely and includes so-called epistemic uses ((2.a) and (2.b)) generic uses ((2.c)) (Palmer, 1986), as well as concessive uses ((2.d)) (Bertinetto, 1979; Berretta, 1997; Squartini, 2012).

(2.a) That will be the postman. (Palmer, 1986)

(2.b.) Ce sera le facteur.

(2.c) Oil will float on water.

(2.d) Sarò stupido, ma non capisco questa teoria. (Bertinetto, 1979)

Be.1SG.FUT stupid, but not understand.1SG this theory.

Existing work on the future tense across languages strives to determine the parameters of variation across languages and this article intends to contribute to this effort by studying certain uses of French future sentences. Current theories build on the observation that in the uses illustrated in (2.a)-(2.d), FUT does not convey future reference; rather it conveys a modal interpretation in both the temporal and the epistemic uses (for the epistemic uses of FUT across languages, see a.o. Bertinetto, 1979; Squartini, 2004; Pietrandrea, 2005; Mari, 2009 for Italian; Enç, 1996; Kissine, 2008 for English; Tasmowski and Dendale, 1998; Dendale, 2001; Celle, 2004 for French; Broekhuis and Verkuyl, 2013 for Dutch; Rocci 2000 for French and Italian; Giannakidou and Mari, 2013 for Italian and Greek).

Research regarding which type of modality FUT conveys has mostly focused on these two uses. The label 'epistemic' interpretation is sometimes replaced by 'conjectural' 
interpretation. What is intended is that the speaker makes a conjecture about the truth of the proposition, just as with epistemic modals (another label found in the literature is 'inferential'). For (2.b), the speaker entertains the belief that the box s/he sees on the desk is the gift from a fan. It is sometimes assumed that the belief is the result of an inferential process using indirect evidence (e.g. Giannakidou and Mari, 2013, to appear-a; for French, Caudal, 2012; a contrario Dendale, 2001). In this case, as we discuss at length later in the article, future sentences seem to be synonymous with epistemic devoir-sentences.

(3) Il est trempé, il doit avoir oublié son parapluie.

http://forum.wordreference.com/showthread.php?t=1879119

The idea has also been defended that FUT and devoir are both universal epistemic modals, ${ }^{2}$ and even for the French future, accounts have been proposed along these lines. Across a variety of frameworks, some recent literature has shown that the boundaries between epistemic modality and evidentiality are not as clear-cut as one might expect (Mithun, 1986; de Haan, 1999, 2001; Nuyts, 2001; Faller, 2002; Matthewson et al. 2007; Narrog, 2012). While it is recognized that evidentials convey information about the source of the information and epistemic modals express the speaker's commitment to the truth of the proposition expressed (e.g. de Haan, 2001; Aikhenvalt, 2004), it has recently been proposed that a variety of expressions across languages convey both modal and evidential meaning. The question arises as to how these two meanings are articulated. Specifically, for English, it has been proposed that must, in its epistemic interpretation, presupposes indirect evidence (in the sense of Willett, 1998; von Fintel and Gillies, 2010). A sentence like That must be the postman

\footnotetext{
${ }^{2}$ In the modal logic tradition and in the formal Kratzerian framework (Kratzer, 1981) developed after it, devoir and pouvoir are represented as quantifiers, by analogy with tous les ('every') and certain ('some'). Their domain of quantification is a set of possible worlds. Devoir is considered to quantify over the entire set of worlds and thus to be a universal quantifier. Pouvoir is considered to quantify over a subset of the set of worlds and thus to be an existential quantifier. For an introduction to these notions, see Mari (2015).
} 
(Palmer, 1967) is not acceptable if the speaker has seen the postman (see also Dendale, 2001 for French, as well as Mortelmans, 2000; Nuyts, 2001; a contrario, for Italian, see Squartini, 2004). The idea is that must and its equivalents across languages can be used felicitously if the speaker grounds his/her assertion in indirect evidence.

Nonetheless, the differences between FUT and devoir provide a key entry into the landscape of FUT and, as already argued, FUT and devoir behave very differently in French compared to other languages (see e.g. for comparison between FUT and universal epistemic modals, Tasmowski and Dendale, 1998; Bertinetto, 1979; Pietrandrea, 2005; Giannakidou and Mari, to appear-a, but also, a contrario, Squartini, 2004). Specifically, it has been argued that devoir is an evidential (see in particular, Dendale, 2001, and also Mortelmans, 2000; Nuyts, 2001 for Dutch), whereas FUT is not. To express a conjecture using FUT, Dendale explains, the speaker does not use evidence available in the context of utterance.

Our starting hypothesis, in line most notably, with Damourette and Pichon (1911), Schrott (1997), Dendale (2001), de Saussure and Morency (2011) is that FUT expresses verification and forward-shifts the time of the verification. In spite of the apparent consensus, there is wide disagreement as to what 'future verification' means. Here we hold (pursuing a hypothesis in de Saussure and Morency, 2011) that FUT contributes a future time of verification, coding temporal and modal information in the semantics (we use the terms verification and ratification interchangeably). The idea that FUT provides temporal and modal information is not new (see also Thomason, 1984; Copley, 2002; Kaufmann, 2005; Giannakidou and Mari, 2013). Here, we assume with de Saussure and Morency (2011) that the modal perspective is future and make explicit that the modal is ratificational.

We disentangle the modal meaning 'ratification' into two components: a modal meaning and an evidential component. Our proposal is that the French FUT contributes modality and that the specific type of modality that it contributes requires that the context of 
the modal evaluation satisfies specific evidential constraints.

Importantly, when modality interacts with time, this constraint on the context holds at the time when the modal is evaluated (this is known by the term 'modal perspective', Condoravdi, 2002). Since the modal perspective is in the future in respect of the utterance time, in line with previous literature FUT does not convey that the speaker uses evidence at the time of utterance (unlike devoir).

We spell out the evidential constraint on the context of evaluation of the modal in a precise way (we call it 'the ratificational modal constraint') arguing that the time of evaluation of the modal and of the prejacent proposition coincide. ${ }^{3}$

From this evidential constraint that the modal imposes on its context of evaluation, we derive in a principled way the available interpretations of the future, including both the temporal and the epistemic interpretation.

In previous conceptions the temporal and the epistemic (conjectural) interpretation of FUT in French have been treated as two separate lexical entries (i.e. it has been assumed that there are two future tenses, which happen to have the same form); however, one of the main concerns of this article is the systematic polysemy of FUT across languages, and the question we ask is how to explain this systematicity.

A number of cross-linguistic studies (a.o. Condoravdi, 2002; Boogaart and Trnavac, 2011; Mari, 2015) have revealed a predominant pattern according to which the epistemic reading arises with statives (the future anterior, manifests this correlation, as we explain later in the article) and the temporal reading arises with eventives. Interestingly, in French, FUT breaks this pattern with simple future sentences, where statives and eventives behave on a par with each other and the temporal reading is the preferred interpretation with both (see e.g.

\footnotetext{
3 The 'prejacent' is the proposition in the scope of the modal. We use 'prejacent' and 'prejacent proposition' interchangeably. The abbreviation will be $p$. The term 'prejacent' is used to refer to a proposition from which another complex proposition can be formed. The modal proposition $[$ modal $+p]$ is obtained by adding the modal on top of $p$, hence the term 'prejacent' for $p$.
} 
Klein, 1980).

We allow for the possibility that the 'ratificational modal constraint' is satisfied to different degrees, and we will thus be able to rank the interpretations in terms of preferences when more than one interpretation is available, appealing to the 'strongest meaning' hypothesis of Dalrymple et al. (1998). When two interpretations are in competition and satisfy the 'ratificational modal constraint' to different degrees, the one that satisfies this constraint to the highest degree is preferred. We will show that the temporal interpretation with both eventives and statives is the one that satisfies the 'ratificational modal constraint' to the highest degree and it is thus preferred over the concurrent epistemic interpretation.

A final note on our model-theoretic assumptions. The temporal-epistemic ambiguity of FUT across languages has been the focus of much attention and in trying to explain this ambiguity, researchers have adopted the Aristotelian idea that future sentences convey some kind of indeterminacy (e.g. Prior, 1957; Thomason, 1984; Copley, 2002; Kissine, 2008; Giannakidou and Mari, 2013).

The discussion turns on whether indeterminacy is metaphysical or epistemic and whether one or multiple types of indeterminacy is/are involved in the epistemic and temporal interpretations of future sentences. Let us consider the utterance time $t_{u}$. The future is determined at $t_{u}$ if there is only one way in which the actual world can evolve. The future is considered to be metaphysically undetermined at $t_{u}$ if it is not already determined what will happen, and options are open. It has been argued that the future is metaphysically determined ${ }^{4}$ and that the indeterminacy is also epistemic (we cannot know what will happen) in the temporal interpretation of future sentences (e.g. Kissine, 2008). It has also been argued that the indeterminacy is metaphysical in the temporal reading (e.g. Prior, 1957; Thomason, 1984; Copley, 2002; Giannakidou and Mari, 2013) and that the indeterminacy is epistemic in the

\footnotetext{
${ }^{4}$ Different authors use different terms to render the idea of metaphysical (in)determinacy. In the literature on modality and Aktionsart, Condoradvi (2002) uses the term '(un)settledness'. Mari (2014) uses the term '(un)decidedness'.
} 
epistemic reading (e.g. Condoravdi, 2002).

In this article, we adopt the model of a metaphysically open future, that is to say the model of an undetermined future. ${ }^{5}$ Metaphysical indeterminacy, however, can go hand in hand with epistemic certainty (pace Condoravdi, 2002), as will be developed in section 5.

Finally, the idea that future sentences articulate futurity and verification has been defended by Kissine (2008). In Kissine's account, FUT only provides tense (present/posteriority). As we will show, this view cannot be extended to French. It is nonetheless interesting to see that French and English code differently the two ingredients of time and verificational modality. This article thus paves the way for future cross-linguistic research on French and English (for earlier views, see Tasmowski and Dendale, 1998; Celle, 2004).

The article is structured as follows. In section 2 we discuss the main data, disentangling FUT from epistemic modality and investigating the systematic polysemy of FUT and its breaches in French. In section 3 we present our main hypothesis. We explain the system of preferences observed in section 4 . In section 5 we consider epistemic certainty as well as epistemic paradoxes that arise with future sentences. Section 6 concludes the paper.

\section{DISENTANGLING FUTURE FROM EPISTEMIC MODALITY}

\subsection{Epistemic devoir vs. conjectural future}

The idea that FUT conveys future verification is solidly established in the literature and it would be an impossible enterprise to do justice to it (a.o. Schrott, 1997; Tasmowski and Dendale, 1998; Dendale, 2001; Morency, 2010; de Saussure and Morency, 2001 and

\footnotetext{
${ }^{5}$ See Thomason (1984); Condoravdi (2002); Kaufmann (2005); Mari (2014) for formal implementations of this model.
} 
references therein). The notion of 'future verification', however, has received many distinct interpretations across the various studies, leading to different conceptions.

Tasmowski and Dendale (1998) and Dendale (2001) are representative of one way of understanding 'future verification'. Dendale (2001) contrasts future tense and devoir and explains that devoir can be used if the speaker has evidence in the utterance context for the truth of the prejacent ( $p$ from now on), while such evidence is not needed in order to use FUT. FUT can be used, Dendale claims, even in the absence of such evidence.

Consider a scenario in which I wonder what is happening to John, who is unexpectedly tired. One of his colleagues asserts the following.

(4) Il doit avoir été malade, il a l'air tout pâle.

(5) Il aura été malade, voilà tout.

In both cases the speaker must have 'indirect' evidence, that is to say, he cannot have seen John ill. However, the devoir sentence requires that the speaker bases his assertion on certain pieces of evidence (e.g. John is pale), but the future sentence does not. The idea then arises that some evidence will be available in the future and that the conjecture will be verified then. In Tasmowski and Dendale's view, future sentences lack truth conditions at the time of utterance (see Tasmowski and Dendale, 1998: 327).

De Saussure and Morency (2011: 209) (S\&M for now on), pick up on the idea of future verification, but include it in the semantics of the future, a path that we follow here.

Our general assumption follows the classical analysis in which FUT in French represents a future verification of a possible state of affairs in the present (or in the past, as with the future anterior). 
There are some cases in which the idea of future verification works particularly well. The following example is due to these authors. Two friends are speculating about the shape of the universe. FUT cannot be used to express a conjecture ((6)). Devoir can be used in this context ((7)).

(6) \#L'univers sera sphérique. (S\&M, 2011: 217, ex. (34))

(7) Il doit être sphérique.

De Saussure and Morency explain the impossibility of (6) by the fact that neither the speaker nor the hearer can directly verify whether the universe is spherical. (This is in contrast with Schrott's (1997) view that the verification has to take place within the sphere of experience of the speaker. De Saussure and Morency are, arguably, less restrictive, and either the speaker or the hearer are good candidates for verifying the truth of the prejacent.)

Devoir is unproblematic in this context, as it expresses conjecture $((7))$. This shows that an inference-based account does not seem to be suitable for French (pace Caudal, 2012).

Unlike devoir, FUT can be used when the speaker knows that the prejacent is true at the time of utterance. Again, the example is due to de Saussure and Morency (2011). A shop employee has just rearranged the shoes on the shelves. A customer enters the shop and asks where the Adidas trainers are. The employee replies (8).

(8) Elles seront sur le présentoir là-bas. (S\&M, 2011: 219, ex. $\left.(37)^{6}\right)$

\footnotetext{
6 The adverbial là-bas has been added to the original example, following the suggestion of de Saussure himself (de Saussure, p.c.).
} 
Here FUT does not express a conjecture. Rather, it postpones the time of verification that the shoes are on the shelf with respect to the time of utterance. Here the hearer (pace Schrott, 1997) will be responsible for the verification (see also Azzopardi and Bres, 2014).

There are other uses of FUT, however, for which theories holding that FUT means future verification must provide a more elaborate account.

FUT, in French, features a truly epistemic (or conjectural use). Consider a scenario in which I have been travelling to Japan and stayed at a hotel. Later, I could not find my watch. My husband utters (9).

(9) Tu l'auras laissée à l'hôtel.

The question immediately arises of what 'future verification' amounts to. Schrott (1997) proposes that with the future anterior and the conjectural interpretation there is a reinterpretation at the de dicto level of the future verification at de re level that characterizes the temporal interpretation. Translating this view into other terms, we would obtain an ambiguity of the future, emerging as a type-theoretical difference: for the temporal interpretation FUT's denotation falls within the domain of events, and in the conjectural interpretation, in that of propositions. This view is certainly tenable and in fact has been advanced more recently by Copley (2002). However, before positing an ambiguity - for the sake of economy of the theory -it behoves us to attempt to provide a unified entry and explain the ambiguity in a systematic way without positing a type-theoretical distinction. The one we provide in this paper will also be able to cover cases that are not easy to categorize in either one of the two classes (de re - de dicto cases) and which clearly fall within a system of preferences. To our knowledge, this has only recently been considered in more depth (see de Saussure and Morency, 2011). 
Let us return to (9). In this interpretation, FUT behaves similarly to devoir (must) $((10))$. In the same scenario, the following sentence is acceptable.

(10) Tu dois l'avoir laissée à l'hôtel.

Note also that FUT cannot be a temporal operator that forward-shifts the time of the event (or one that locates the event, at the earliest, at the time of utterance; see Kissine, 2008). If FUT were such an operator, a future-in-the-past reading would be obtained for (10), contrary to fact. (10) conveys that, according to what the speaker knows at the time of utterance, I left the watch at the hotel in the past (this is parallel to Italian, see Mari, 2009; Gianakidou and Mari, 2013, to appear-a).

De Saussure and Morency (2011) propose that FUT means future verification of a present conjecture. The delicate question arising is at what level 'conjecture' and 'verification' are coded, a question that we discuss in detail in section 5.

Let us return to the hypothesis that FUT denotes future verification and to a case that is acknowledged as difficult by de Saussure and Morency themselves. We label this the 'present ratification' use (this use is also called 'futur expansif' (Wilmet, 1976), 'futur de retrospection' (Wagner and Pichon, 1991) or 'futur de bilan' (Maingueneau, 1981; Caudal, 2012).

(11) Au-delà des résultats obtenus, le grand mérite de cet expert-tacticien aura été de créer le consensus autour de sa propre personne.

Le Monde, 12 June 1998, p. 15

(12) Si Buzz Aldrin a été le second homme à poser le pied sur la Lune, il aura été le premier à léviter quelques centimètres au-dessus du sol sur le mythique overboard. 
http://www.20minutes.fr/high-tech/1471391-20141030-astronaute-buzz-aldrin-testehoverboard

In view of these cases, a series of questions arises. Does FUT denote 'present conjecture'? Not always. It seems to do so unproblematically only in (9). Does FUT denote future verification? Again, not always. In some cases, future verification is impossible and the sentence is true $((9))$. In some other cases, the speaker knows at the time of utterance that it is true $((11))$.

An adequate theory of the future, we claim, must be able to explain the facts summarized in Table 1 (see below). Like devoir, FUT seems to be able to convey present conjecture. This conjecture is grounded in indirect evidence ((9)). Unlike devoir, FUT can use direct evidence ((11)). Unlike devoir, it can denote future verification ((8)).

\begin{tabular}{|c|c|c|c|}
\hline & $\begin{array}{c}\text { Absence of } \\
\text { vérification. } \\
\text { Conjecture. }\end{array}$ & $\begin{array}{c}\text { Present ratification. } \\
\text { Present knowledge. }\end{array}$ & $\begin{array}{c}\text { Future vérification. } \\
\text { Future knowledge. }\end{array}$ \\
\hline FUT & $(9)$ & $(11)$ & $(8)$ \\
Devoir & $(10)$ & no & no \\
\hline
\end{tabular}

Table 1: Interpretations of FUT and devoir.

The diversity of these uses is puzzling. Thus, one of the goals of this paper is to propose a theory that explains these distributions in a principled way. Let us note that we do not claim that these are all and only the available uses of the French FUT (see for instance Azzopardi and Bres, 2014 for discussion of the 'future of assertion' and the 'discovery' use). We also do not consider here the rhetorical values of FUT in French (see Rossari et al., 2014). To achieve our goal, we examine the evidential component of the ratificational modal, also considering the effects of this component on the system of preferences observed, to which we now turn. 


\subsection{Breaking the cross-linguistic pattern ${ }^{7}$}

It is now a common observation that the epistemic/non-epistemic ambiguity of modals correlates with the aspectual properties of the complement they combine with (see most notably Sueur, 1979; Condoravdi, 2002; Copley, 2002; Malchukov, 2009; Boogaart and Trnavac, 2011; Caudal, 2012; Giannakidou and Mari, to appear-a). Statives (including lexical statives, resultatives, and progressives) correlate with the epistemic interpretation ((13.a)(14.a)), while eventives ((13.b)-(14.b)) correlate with non-epistemic interpretations (including the deontic, metaphysical, ...).

(13.a) He is not at school, he might be ill. (epistemic)

(13.b) If he does not wear his raincoat, he might become ill. (circumstantial ${ }^{8}$ )

(14.a) The lights are on. John must be at home. (epistemic)

(14.b) John must go home, his mother is waiting for him. (deontic)

The same pattern is illustrated by FUT in French, most clearly by the future anterior. Simple future sentences with eventives feature the temporal interpretation $((15))$, whereas future anterior sentences feature the epistemic interpretation ((16)).

Jean mangera de la pizza ce midi. (temporal)

John eat.3SG.FUT of the pizza this noon.

'John will eat pizza at lunch.'

Jean aura mangé de la pizza, il a une moustache rouge.

\footnotetext{
7 Glosses and translations are provided in this section to facilitate cross-linguistic comparison.

${ }^{8}$ Note that the epistemic interpretation is also possible, as circumstantial indeterminacy induces epistemic uncertainty.
} 
John have.3SG.FUT eaten of the pizza, he has a moustache red.

'John must have eaten pizza, he has a red moustache.'

As a reviewer points out to us, ${ }^{9}$ in French, future anterior sentences must be treated like statives. This can be demonstrated by the fact that when a temporal adverbial (à 4 heures) is used with the future anterior, it locates the time of the result ((17.b)), and not the time of the event, unlike with simple future sentences ((17.a)) (see also Kevers, 2011).

(17.a) Jean terminera

ce test à 4 heures.

John complete.3SG.FUT this test at 4 hours.

'John will complete this test at 4pm.'

Jean aura terminé ce test à 4 heures.

John have.3SG.FUT completed this test at 4 hours.

'John will have completed this test at 4pm.'

Note that in (17.b), the event of completing the test can take place after the time of utterance. When the event is located in the past, a temporal adverb can locate the time of the event rather than that of the result, as in (18), given in response to the question 'Where is my watch? I cannot find it.'

(18) Tu l'auras

laissée hier à l'hôtel.

You it-have.3SG.FUT left

yesterday at the-hotel.

'You must have left it at the hotel yesterday.'

\footnotetext{
${ }^{9}$ We thank an anonymous reviewer for examples (17.a)-(17.b).
} 
Here the adverb hier (yesterday) locates the event of leaving the watch at the hotel rather than the time of the result.

For all these cases, we endorse the view that the future anterior involves a resultative construction (see also Gosselin, 1996; Vet, 2007) and has to be treated as a stative, most notably following a recent analysis in Boogaart and Trnavac (2011). Importantly for us, this resultative construction (which we label $\operatorname{RES}(p)$ ) provides a handle for the evidential component of the ratificational modal as we explain in detail in section 3 .

Thus far, French FUT seems to align with modals across languages. The epistemic interpretation of devoir arises with statives and the root (metaphysical, deontic, temporal, ...) interpretation arises with eventives (see Condoravdi, 2002).

(19.a) Il doit être malade. (epistemic)

He must be ill.

'He must be ill.'

(19.b) Il doit avoir été chez le médecin. (epistemic)

He must have been at the doctor.

'He must have gone to the doctor.'

(19.c) Il doit aller chez le médecin. (deontic)

He must go at the doctor.

'He must go to the doctor.'

Most of the accounts we are aware of derive the facts by relying on the boundednessunboundedness difference (or, alternatively, the perfective-imperfective distinction, or the eventive-stative distinction). That boundedness correlates with forward-shifting is sometimes considered a primitive of the theory (Condoravdi, 2002). According to Boogaart and Trvanac 
(2011) (see also Caudal, 2012), bounded temporal entities induce an external point of view and thus may explain futurity with respect to the main perspectival point, which is the time of utterance (when the event is not otherwise located in the past).

A closer look, however, reveals that this pattern is disrupted with statives in simple future sentences in French, breaching the systematic ambiguity observed cross-linguistically. Both sentences in (20)-(21) have a preferred temporal use, regardless of whether an eventive or a stative predicate is used.

(20) (...) en raison de la forte démographie des travailleurs hispaniques, ... un catholique sur deux parlera espagnol aux Etats-Unis en l'an 2000.

'Because of the high proportion of Hispanic workers, ... every other Catholic will speak Spanish in the USA in 2000.' (Le Monde, 22 September 1987, p.1)

(21) Sachant qu'une personne était malade au jour 1 et que chaque malade contamine deux nouvelles personnes le jour suivant, vous devez calculer à partir de quel jour toute la population de la ville sera malade.

'Knowing that one person was ill on day 1 and that every sick person contaminates two new persons the subsequent day, you should calculate from the day on which the whole population of the town will be ill.'

http://openclassrooms.com/forum/sujet/application-en-medecine-17105

The preference for the temporal interpretation with statives is to some extent unexpected. This position needs to be qualified, and revised to some extent (cf. infra). Prima facie, though, it seems to capture a clear preference, to the point that it has been claimed that the epistemic interpretation is not available for simple future sentences (Klein, 1980).

Examples of the epistemic interpretation of simple future sentences with statives are in- 
deed discussed in the literature. (22) is from Baranzini and de Saussure (2014) (B\&S, 2014; slides presented at the Chronos conference in Pisa, 2014).

(22) A l'heure qu'il est, il sera à la piscine. By now, he be.3SG.FUT at the swimming-pool. 'By now, he must be at the swimming-pool.'

(23) Il aura encore sa migraine. (Sten, 1954: 61)

He have.3SG.FUT again his headache.

'He must still have his headache.'

While the predominant absence of the epistemic interpretation with eventives is no surprise given the cross-linguistic pattern, there are in fact examples of epistemic readings with eventives. One famous example discussed in the literature is from Chevalier (1978: 352) - cited in Dendale (2001: 4):

(24) Notre ami est absent. Il présidera quelque réunion. (Chevalier, 1978: 352)

Our friend is absent. He chair.3SG.FUT some meeting.

'Our friend is absent. He must be chairing some meeting.'

It is however to be noted that this is a stative in disguise, as the possibility of using a durational adverb with pendant (during) shows (We thank an anonymous reviewer for this observation).

De Saussure and Morency (2011) were the first to tackle the difficult question of the conditions that make the epistemic interpretation with eventives possible. There is considerable agreement that the epistemic interpretation is very difficult. Consider a scenario 
in which Mary is on a train, her telephone rings, but she does not answer. A friend of mine, who is waiting for Mary with me at the train station, tries to figure out why she is not answering. I reply (25). Out of the blue, the utterance is not natural.

(25) \#Son train traversera

un tunnel. (S\&M, 2011: 214, ex. (10)).

Her train go-through.3SG.FUT a tunnel.

Morency (2010) and de Saussure and Morency (2011), crediting Sthioul (2007) - have claimed that naturalness is restored in non-stative sentences, in scenarios where the event of verification is overt (in (26) the verification event is that of asking Pierre).

(26) A: J'ai une fuite dans la salle de bain! (S\&M, 2011: 219, ex. (19) $\left.{ }^{10}\right)$

B: Demande à Pierre, il connaîtra un plombier $!^{11}$

A: 'There is a water leak in my bathroom !'

B: 'Ask Pierre, he will know a plumber!'

These preferences are puzzling. On the one hand there is a clear preference for the temporal interpretation of simple future sentences in French with both eventives and statives. On the other, statives are also quite readily compatible with the epistemic interpretation, and the latter can be forced with eventives, in particular when a future event of verification is overtly mentioned.

An adequate theory of FUT in French, it seems, requires that we find an explanation of the epistemic / temporal ambiguity of FUT in French which does not rely entirely on lexical

\footnotetext{
10 See Morency (2010: 208) for an in-depth discussion of this example.

${ }^{11}$ Here 'connaitre un plombier' is not a stative, as the incompatibility with pendant adverbials shows: *Il connaîtra un plombier pendant des années. See discussion in Morency (2010: 208).
} 
aspect (i.e. Aktionsart), and can provide the following empirical coverage:

(i) the preference for a temporal interpretation with both eventives and statives for simple future sentences;

(ii) the availability of the epistemic reading with statives in simple future sentences;

(iii) the impossibility of the epistemic reading with eventives in the absence of the rescuing strategy' of mentioning a future event of ratification;

(iv) the unproblematic compatibility of the epistemic interpretation with the future anterior.

While all the work that we are aware of acknowledges these preferences, we know of no previous attempt to explain them in a principled way. The view we are about to present covers these preferences, and makes sense of the distributions observed in section 2.1, without appealing to semantic ambiguity.

\section{THE HYPOTHESIS}

\subsection{Ratificational modality}

Our hypothesis is that FUT in French makes a triple contribution, at different levels: temporal, modal (in the semantics) and evidential (in the pragmatics). That FUT contributes modality and temporality is now a common assumption in the literature on FUT across languages (cf. among many others, Thomason, 1984; Kaufmann, 2005; de Saussure and Morency, 2011; Giannakidou and Mari, to appear-a). In line with the previous literature on the matter, as already mentioned, we build on the assumption that FUT forward-shifts the time of evaluation of the modal (or, in other terms, represents future verification; cf. Schrott, 1997; de Saussure and Morency, 2011). The evidential dimension of the modal and the role it plays in the interpretations has instead been left out of account. 
Research on epistemic modals (whether veridical or conjectural), has explored the hypothesis that these impose constraints on the context regarding the type of evidence available at the time of evaluation of the modality. Karttunen (1972), Dendale (2001), Nuyts (2001), von Fintel and Gillies (2010), Giannakidou and Mari (to appear-a) - just to mention a few works from different frameworks - have explored the idea that must and its equivalent in other languages (such as French, Dutch, Greek and Italian) presupposes indirect evidence. Recall that, in order to felicitously utter (27), the speaker must not have seen the rain, but must have some indication that it is raining.

(27) It must be raining.

Importantly, when modality interacts with time, this constraint on the context holds at the time when the modal is evaluated. Let us provide an example independent of the French FUT. It is well known that a modal in the imperfect in French can have an epistemic meaning and can be evaluated in the past (see Boogaart and Trnavac, 2011; Mari, 2015). Consider a scenario in which my husband sees that the drawer of the table is open, and asks me why it is open. I can reply (28) (discussed a.o. in Mari, 2015).

(28) Je cherchais les clés, et elles pouvaient être dans le tiroir.

At the time of evaluation of the epistemic modal (which is past), the speaker had evidence (in this case, indirect, inferential evidence) that the keys were in the drawer. Indirect evidence that is available in the past is a constraint on the context, at the time of evaluation of the modal.

Our hypothesis is thus that the future contributes a temporal component which forward- 
shifts the time of evaluation of the modal component. The modality is ratificational and imposes an evidential constraint on the context of evaluation. As a consequence, FUT does not convey the fact that the speaker/hearer uses evidence at the time of utterance (unlike what has been argued for devoir, and in line with e.g. Dendale, 2001).

We now turn to the evidential constraint imposed by the modal. We propose the following principle (29) for FUT as a ratificational modal.

(29) Ratificational modal constraint. If a modal is ratificational, then the time of evaluation of the prejacent and the time of evaluation of the modal must coincide. ${ }^{12}$

When the time of evaluation of the ratificational modal and of the prejacent do not coincide, ratification proceeds indirectly.

(30) Weakening of the ratificational modal constraint. If the time of evaluation of the modal and of the prejacent do not coincide, then ratification is indirect.

Our view of the evidential meaning attached to the modal component is one that considers it as a constraint on the relation between the time of evaluation of the modal and the time of evaluation of the prejacent. The notion of 'direct evidence' boils down to the temporal constraint that the time of evaluation of the modality (the time of acquisition of knowledge) and the time of evaluation of the prejacent coincide. This is a felicity constraint that the modal imposes on the context of its evaluation. ${ }^{13}$

\footnotetext{
12 Note that the reverse does not hold. If the time of evaluation and of the modal coincide, the modal is not necessarily ratificational and can be conjectural.

13 Our account shares some features with Lee's (2012) analysis of Korean evidential -te. Lee has argued that -te expresses that the speaker has sensory information about the described eventuality and that this sensory information is available at the time of utterance. Interestingly, -te can express direct or indirect sensory information depending on the tense it combines with. When it combines with the past tense, it can only mark
} 


\subsection{The ratificational modal constraint, FUT, and the effects on temporality}

We have argued that FUT forward-shifts the time of evaluation of the ratificational modal. The ratificational modal is felicitously used if the judge has direct evidence at the time of evaluation of the modal. In our account, the constraint of direct evidence boils down to a temporal constraint that the time of evaluation of the modal and of the prejacent must coincide. Let us now consider how different interpretations of future sentences in French deal with this constraint. We propose to analyze simple future sentences as in (31) (see below).

We have stated that FUT represents future verification, in line with previous proposals. It is thus a complex operator that introduces temporal and modal information, and forwardshifts the time of evaluation of the modal. On the other hand, the time of evaluation of the prejacent (we assume that propositions are evaluated not only with respect to worlds, but also to times) can be either the present (in the conjectural interpretation) or the future (in the temporal interpretation). The temporal argument of the prejacent is thus not saturated by FUT. For simple future sentences, in line with Abusch (2004) and Giannakidou and Mari (2013, to appear-a), we reconstruct an element NON-PAST, which locates the prejacent either at utterance time, or at a time that follows the time of utterance. ${ }^{14}$ This leads to the intended interpretation, in a compositional framework, according to which FUT contributes future verification of a proposition whose time of evaluation is either the utterance time or a future time.

indirect evidence. Lee thus proposes that direct information requires that the time at which the evidence is available and the time of the eventuality coincide. When the time at which the evidence is available and the time at which the eventuality takes place do not coincide, -te can only mark indirect information. -te always has present perspective, that is to say, differently from FUT, its time of evaluation is the time of utterance. Lee notes that -te can also be combined with the future tense and thus receives a conjectural interpretation. The point of similarity between ours and Lee's account is the notion that having direct evidence means that the time of the evaluation of the modal (in the case of FUT)/evidential (in the case of -te) coincides with the time of evaluation of the prejacent.

14 See also Abusch (2004); Giannakidou and Mari (to appear-a); formally, NON-PAST provides an interval that starts at the time of utterance and goes on to infinitum as well as quantification over a time in this interval. 


\section{(31) FUT(NON-PAST $(p))$}

There is a time in the future of the utterance time at which a judge verifies whether $p . p$ can be evaluated at $t_{u}$ or at a $\mathrm{t}^{\prime}, t^{\prime}>t_{u}$. $\left(t^{\prime}>t_{u}\right.$ means that $t^{\prime}$ occurs later than $\left.t_{u}\right)$.

The question to be settled is thus what the time of evaluation of the prejacent is, as this can be either the time of utterance or a future time. By addressing this question, we ask under what conditions the temporal and the conjectural interpretations are obtained. Note that here, we are positing an underspecified lexical entry for both of them. What is underspecified for now is the time of evaluation of the prejacent, and this is what the evidential constraint allows us to establish.

As we have argued, the ratificational modal constraint requires that, if possible, the prejacent should be evaluated at the time of evaluation of the ratificational modal, which is in the future with respect to the time of utterance. This straightforwardly allows us to predict that, for simple future sentences, the temporal interpretation is the preferred one (we will return in section 4 to the system of preferences).

As depicted in Figure 1, in order to satisfy (29), the time of evaluation of $p$ is fixed as being in the future with respect to utterance time and as coinciding with the time of evaluation of the modality. We use VER for 'verification'.

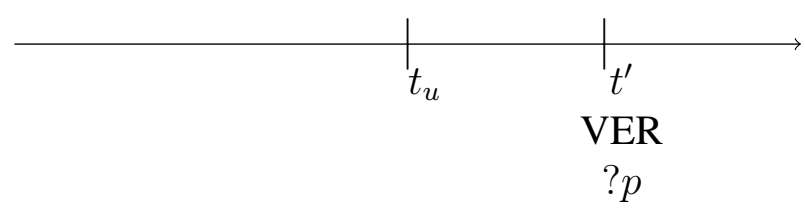

Figure 1: Simple future sentences

We place a question mark next to $p$ to indicate that it is not metaphysically determined whether $p$ will be true in the actual world (and thus will be known to be true). Recall that we 
are working with metaphysical indeterminacy, endorsing the view according to which it is not determined whether the actual world to come (depicted as a line from $t_{u}$ to $t^{\prime}$ ) will be a $p$ world or not. As we argue in section 5, the matter is settled only from the speaker's perspective. $^{15}$

As formulated, (31) allows us to derive the temporal interpretation of simple future sentences. The ratificational modal constraint thus has an effect on temporality, as it requires that the time of evaluation of the prejacent coincides with the time of evaluation of the modal.

As a consequence, our hypothesis immediately accounts for the fact that with the simple future, the temporal interpretation is overwhelmingly obtained. The following example is the actual announcement of a TGV arrival at Avignon station.

(32) Le train arrivera en gare d' Avignon dans quelques instants.

We return in section 5 to the epistemic interpretation of simple future sentences.

A more interesting example is (8), repeated here as (33). Recall that in the scenario proposed by de Saussure and Morency, the employee has herself put the shoes on the shelf. Asked by a customer where the shoes are, she replies (33):

(33) Elles seront sur le présentoir là-bas. (S\&M, 2011: 219, ex. (37))

The customer (i.e. the 'addressee' here) is responsible for verifying where the shoes are. ${ }^{16}$ FUT provides a future time of verification.

As for future anterior sentences, they are decomposed as in (34.a) (we specifically

\footnotetext{
15 In some languages, like Italian, FUT also codes the hearer's perspective at the time of utterance and certainty, as also with the concessive future (see Squartini, 2012).

${ }^{16}$ Note that here the addressee's perspective is future and not present.
} 
consider cases in which the event is located before the time of utterance).

As for (9) (repeated here as (34.b)), the perfect provides a proposition that describes the resulting state of the event described in the prejacent proposition $p$. At a future time, a judge (the addressee, here) can only witness the result of the event described in $p$ rather than the event in $p$ itself. Verification will thus proceed via indirect evidence (see Figure 2, below). Note that even in this case, we are arguing that FUT represents future ratification. As the time of evaluation of the prejacent and of the verificational modal cannot coincide, there is weakening and the ratification will proceed via indirect evidence (see (30)). Importantly though, future verification is still represented in the semantics.

(34.a) $\operatorname{FUT}(\operatorname{RES}(p))$ There is a time in the future with respect to utterance time, at which a judge verifies whether $\operatorname{RES}(p)$ holds.

(34.b) Context: I cannot find my watch any more.

Tu auras laissé ta montre à l'hôtel.

We obtain the following (see Figure 2).

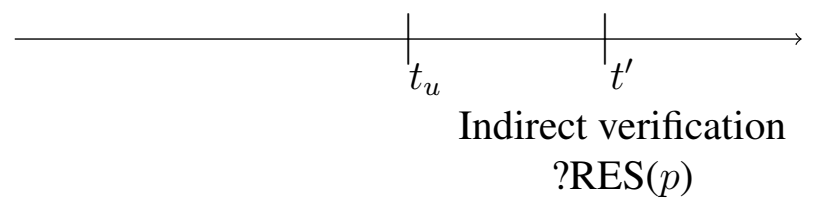

Figure 2: Future anterior sentences

As for (34.b), $\operatorname{RES}(p)$ is the proposition describing the state of having left the watch at the hotel. The truth of the proposition which describes leaving the watch at the hotel can no longer be verified 'directly', but only indirectly. The sentence thus conveys that, in the future, the judge will have indirect evidence for determining the truth of such a proposition. 
Up to now, we have proposed that FUT represents future verification in all cases (including the epistemic case with the future anterior). At this point a number of issues still require an explanation. First, we must explain the system of preferences observed (see section 2.2). Second, we must show how we deal with the so-called epistemic interpretation of simple future sentences and more generally clarify the nature of the 'conjecture' in the epistemic interpretation (see section 5).

4 'MAXIMIZE FELICITY' AND THE PREFERENCE FOR THE TEMPORAL INTERPRETATION OF SIMPLE FUTURE SENTENCES

The discussion in section 2.2 highlighted a system of preferences. Our conclusions were the following. The temporal interpretation is the default for simple future sentences regardless of whether the predicate under the modal is eventive or stative. The epistemic interpretation is unproblematic for future anterior sentences. We consider here only simple future sentences, focusing on their 'epistemic' interpretation.

The epistemic interpretation is widely associated with statives. Let us repeat the relevant examples.

(35) A l'heure qu'il est, il sera à la piscine. (B\&S, 2014; Paper presented at the Chronos conference, Pisa, 2014)

(36) Il aura encore sa migraine. (Sten, 1954: 61)

The epistemic interpretation of simple future sentences with eventives is rarely in evidence, but cannot be ruled out entirely. The relevant cases are repeated here for clarity. 
(37) A: J'ai une fuite dans la salle de bain ! (S\&M, 2011: 219, ex. (19))

B: Demande à Pierre, il connaîtra un plombier !

We now show that this system of preferences can be explained by considering the status of the ratificational modal constraint and how aspectual distinctions deal with it, thereby proposing an alternative to accounts that rely only on aspectual distinctions and points of view.

Let us recall that, with simple future sentences, the time of evaluation of the prejacent is either $t_{u}$ or $\mathrm{t}^{\prime}>t_{u}$. The temporal interpretation is obtained when the prejacent is evaluated at $t^{\prime}$ and the conjectural interpretation arises when it is interpreted at $t_{u}$. We have explained, that, in virtue of (29), by default, the prejacent in simple future sentences is evaluated at a future time. We must now explain the competition with the epistemic interpretations, as this is also available, although dispreferred.

We have claimed that the ratificational modal constraint can be weakened, and, indeed, we have allowed for such weakening: see (30). In other words, this amounts to stating that the ratificational modal constraint can be satisfied to different degrees, depending on whether the time of evaluation of the prejacent coincides or not with the time of evaluation of the modal. Specifically, it is satisfied to the highest degree if the time of evaluation of the modal and of the prejacent coincide. It is satisfied to a lesser degree if this is not the case. The higher the degree to which the felicity constraint (i.e. the ratificational modal constraint) is satisfied, the stronger the interpretation of the sentence. The idea of strength correlates with the ranking of direct and indirect evidence as evidence for acquiring knowledge. Direct evidence ranks higher than indirect evidence.

Following Dalrymple et al. (1998), we propose that when multiple interpretations for a given form are in competition, the strongest one is preferred (this is known as the strongest 
meaning hypothesis - SMH). In our setting, the strongest interpretation is the one that best satisfies the ratificational modal constraint. Recall that the ratificational modal constraint is a condition imposed on the context of evaluation of the modal introduced by FUT and it is thus a felicity condition. We propose the following principle for maximization of the felicity condition associated with FUT.

(38) Maximize felicity. If multiple interpretations are in competition in a given context, choose the one that best satisfies the felicity conditions of FUT.

For simple future sentences, as observed, two interpretations are in competition: the temporal and the epistemic interpretation.

Let us consider eventives first. In the temporal interpretation, the ratificational modal constraint is satisfied to the highest degree, as the time of evaluation of the modal and of $p$ coincide. If the time of evaluation of the modal and of $p$ do not coincide, and $p$ is evaluated at the time of utterance, only indirect verification is allowed. On the temporal interpretation, the ratificational modal constraint is satisfied to the highest degree with eventives, and it is thus the strongest. According to the SMH, it is the preferred one as well, in virtue of (38). This explains why the temporal interpretation is the default one for simple future sentences.

Let us consider statives. On the conjectural interpretation, the time of evaluation of the prejacent is $t_{u}$. FUT nonetheless represents future verification. With many authors (see e.g. the extended discussion of Aktionsart in modal contexts in Condoravdi, 2002; de Saussure and Morency, 2011; Mari, 2014), we assume that statives are associated with an inference of persistence. Unless otherwise stated, a stative eventuality holds for an unbounded period of time. With statives, the ratificational modal constraint can also be satisfied when the time of evaluation of the prejacent is also $t_{u}$. The epistemic interpretation of FUT is thus better 
accepted with statives than with eventives. It is nonetheless dispreferred compared to the temporal interpretation. This is probably due to the complexity of the interpretation that appeals to the inference of persistence with statives.

Using a system of preferences, we are now able to explain why the temporal interpretation of FUT is predominantly preferred, but also why the epistemic interpretation is not ruled out. It is available but it is dispreferred.

With the future anterior, verification can only be indirect. Since this is the only possibility allowed (and thus is not in competition with any other interpretation), the epistemic interpretation is unproblematic.

Note that, for the time being, we have simply stated that under the epistemic interpretation, $p$ is evaluated at the time of utterance. We need to say more about the status of the 'epistemic interpretation' and consider it more closely in relation to future verification.

\section{EPISTEMIC SETTLEDNESS AND THE CONJECTURAL EFFECT}

\subsection{There is no inference of uncertainty}

There is a general consensus for proposing that, if FUT conveys future verification, then at the time of utterance, the speaker is in a state of uncertainty (either about the future (in the temporal reading) or the present (in the epistemic reading). ${ }^{17}$

Strikingly, however, future sentences can manifest Moore's paradox. Discovered by the English philosopher Moore, this paradox is the phenomenon whereby the combination (using either and or but) of two logically compatible propositions results in a contradiction. Moore's paradox features epistemic modals such as must or epistemic attitude predicates such as believe and for this reason it belongs to the class of epistemic paradoxes.

\footnotetext{
17 See Sweetser (1990); Narrog (2001); Dendale (2001).
} 
Moore's paradox has been used to show that epistemic must does not allow for uncertainty (for a discussion of this paradox in the linguistic literature, see Kissine, 2008; von Fintel and Gillies, 2010; Giannakidou and Mari, to appear-a): see (39) (pace Karttunen, 1972). If must allowed for uncertainty (or 'weakness', in Karttunen's words), the perhaps continuation would be acceptable.

(39) It must be raining, \#but perhaps it is not raining.

The same observation can be replicated for future tense (see Kissine, 2008).

(40) Il arrivera à 4 heures, \#mais peut-être il n'arrivera pas à 4 heures.

(41) Tu auras laissé ta montre à l'hôtel, \#mais peut-être tu ne l'auras pas laissée à l'hôtel.

This shows straightforwardly that there cannot be an inference of uncertainty, as the peut-être continuation would have been allowed. In other words, future sentences convey the idea that the speaker is confident that $p$ will be verified as being true.

This conclusion is also in line with Schrott's (1997) claim that FUT involves commitment. Whereas future sentences exploit future metaphysical indeterminacy, they convey epistemic certainty.

Nonetheless, there seem to exist contradictory data to the claim that future sentences convey certainty, most notably in relation to the use of epistemic adverbs (see Tasmowski and Dendale, 1998; Dendale, 2001; Kissine, 2008). FUT is indeed compatible with such adverbs, including weak ones such as maybe.

Note that the same variety of adverbs can be used in both the epistemic and the temporal readings, regardless of whether the time of evaluation of the prejacent is utterance time 
((42)-(43)) or a future time ((44)-(45)) (examples accessed in February 2015).

(42) Mais il aura certainement oublié que ce souhait n'avait pas de chance d'être exaucé tant que le nord du pays resterait entre les mains des rebelles.

http://www.guineeconakry.info/article/detail/duel-dentre-deux-tours-francois-hollandeplus- debatteur-que-prevu/

(43) Il aura peut-être voulu dénoncer, comme déjà un certain Jean-Jacques Servan-Schreiber avant lui dans les années 70, une économie de marché.

http://www.lejournaltoulousain.fr/archives/points-de-vue/liberte-de-pensee/leffet-canto1622

(44) Je tomberai sûrement toujours en marchant. Je me cognerai sûrement encore. http://que-des-belles-paroles.skyrock.com/2877600006-Mes-cheveux-ne-serontjamais-parfait-ma-frange-partira-toujours-en.html

(45) 'On partira peut-être pas en vacances ensemble', précise l'ex-entraîneur de l'Olympique de Marseille.

http://www.lexpress.fr/actualite/sport/football/didier-deschamps-ne-partira-peut-etrepas- en-vacances-avec-laurent-blanc_1201022.html

The role of these adverbs in modal sentences would require a whole study in itself, which we leave for future investigation. We only note with Bonami and Godard (1998) and Ernst (2009) that these are adverbs that take the whole proposition in their scope.

One option is to assume that the decomposition of a sentence like (45) is as in (46).

(46) $\operatorname{MAYBE}(\operatorname{FUT}(p))$ 
It is not settled in the literature whether adverbs contribute expressive meaning (e.g. Mayol and Castrovejo, 2013; Giannakidou and Mari, to appear-b) or whether they are syntactically complex (Kissine, 2008). We do not take a position on this issue.

What matters for us is that on both these views, FUT is not a quantifier of unspecified force, as Dendale (2001) seems to assume (although Dendale does not overtly mention quantification for FUT, he nonetheless proposes that FUT does not always reveal certainty). If its force were unspecified, it would not manifest Moore's paradox and the sentence in (40) would be acceptable.

Overall, we do not endorse the view according to which there is an inference of uncertainty in the use of FUT. So where does the 'conjectural interpretation' of statives and future anterior come from? Our proposal, which we present in the next section, is that the conjectural effect does not correlate with uncertainty, but with indirect evidence.

\subsection{Epistemic inference and indirect evidence}

Thus far, we have argued that future sentences represent future verification (direct or indirect), and that, in the epistemic reading, the prejacent (or $\operatorname{RES}(p)$ ) is evaluated at a future time.

We propose that the 'conjectural interpretation' is indeed an inference that arises when the object of the verification ( $p$ or $\operatorname{RES}(p))$ already holds at the time of utterance and the speaker has no direct evidence. The speaker nonetheless believes that $p$ or $\operatorname{RES}(p)$ is true at $t_{u}$, and has indirect evidence grounding his/her belief. We call this inference the 'epistemic effect.' If the judge acquires direct evidence in the future, at the time of utterance, s/he only has indirect evidence. Our bottom line is that there is not, semantically, a 'conjectural' future, but only a 'conjectural effect' defined as an inference. Thus we use the label 'conjectural 
interpretation' somewhat improperly to target those cases in which the 'conjectural effect' arises. $^{18}$

Note that having indirect evidence and basing a conjecture on indirect evidence at the time of utterance is not a requirement on the context at this point. FUT represents (semantically) future verification only. In (8), the speaker has direct evidence (the employee knows where the shoes are at the time of utterance) and the future sentence is acceptable. In this case, the 'conjectural effect' does not arise, and the sentence conveys future direct verification.

We can derive a parallel conclusion for future anterior sentences. FUT always represents future ratification. In the conjectural interpretation evident in examples (9)-(18), $\operatorname{RES}(p)$ holds at the time of utterance. At this time, the speaker has indirect evidence and the conjectural effect arises.

This epistemic inference (again, not an inference of uncertainty) can be cancelled with the future anterior as well, and this is what happens with the 'present ratification use' (also called (Caudal, 2012) the 'futur de bilan'). In example (11), repeated here as (47), the speaker has the requisite knowledge at the time of utterance.

(47) Au-delà des résultats obtenus, le grand mérite de cet expert-tacticien aura été de créer le consensus autour de sa propre personne. (Le Monde, 12 June 1998, p. 15)

This case is parallel to (8), where the speaker already has knowledge at $t_{u}$ and nonetheless represents future ratification. ${ }^{19}$ The 'present ratification' is typically employed in contexts

\footnotetext{
18 As von Fintel and Gillies (2010) argue, having indirect evidence does not necessarily correlate with 'uncertainty' or weakness (as is the case in Karttunen's, 1972 account).

19 We note with Caudal (2012) that epistemic adverbs are incompatible with the 'present ratification use'. Our account explains this incompatibility by the fact that (i) these adverbs are always speaker-oriented and presentoriented (see above, Bonami and Godard, 2008; Ernst, 2009) and (ii) at the time of utterance the speaker has
} 
where notable facts are being presented. Future generations will be in charge of the verification, just as in (8), the hearer will be in charge of the verification. Recall also (12) repeated as (48).

(48) Si Buzz Aldrin a été le second homme à poser le pied sur la Lune, il aura été le premier à léviter quelques centimètres au-dessus du sol sur le mythique hoverboard.

http://www.20minutes.fr/high-tech/1471391-20141030-astronaute-buzz-aldrin-testehoverboard

By using FUT while in possession of knowledge about the resulting state at the time of utterance, the speaker conveys the persistence of that state and its future verifiability.

Overall, from the perspective of the speaker, cases (8), (47) and (48) are parallel. FUT represents future ratification, but the epistemic inference is cancelled as the speaker has knowledge at the time of utterance. Our conclusion is thus that there is no such thing as a 'conjectural interpretation' coded in the semantics of the future. There is an epistemic inference, which arises when (i) $p$ and $\operatorname{RES}(p)$ already hold at $t_{u}$, and (ii) the speaker has indirect evidence at $t_{u}$. This epistemic inference can be overridden, and a future sentence can be felicitously uttered when the speaker has direct evidence that $p$ (or $\operatorname{RES}(p)$ ) is true at $t_{u}$ (as in (8), (47) and (48)).

\section{Conclusion}

In this paper we have defended a new view of French FUT, which treats it as a ratificational modal whose time of evaluation is forward-shifted, in line with previous literature on the

\footnotetext{
'knowledge' which is conceptually not gradable. These two requirements are in conflict, and the ban on these
} adverbs in this particular use is explained. 
subject. The key ingredient in our account is the ratificational modal constraint that is attached to ratificational modality, requiring that the time of evaluation of the modal and of the prejacent coincide, whenever possible. We have also allowed for weakening of this constraint and proposed that it can be satisfied to different degrees, depending on whether or not the time of evaluation of the modal and of the prejacent coincide. In the first case evidence for assessing the truth of $p$ is direct, but in the second, it is indirect.

We have proposed a unified account of the temporal and epistemic uses, in which the time of evaluation of the prejacent is unspecified and is fixed via the ratificational modal constraint. When more than one interpretation is available (i.e. the time of evaluation of the prejacent can be either the utterance time or the future of the utterance time), the ratificational modal constraint disambiguates according to the strongest meaning hypothesis: the interpretation that best satisfies the constraint is the strongest. The constraint is best satisfied when evidence is direct rather than indirect.

Besides deriving in a principled way the temporal and the epistemic interpretation without positing ambiguity, we also propose a new understanding of the systematic ambiguity of the future. Positing ambiguity would not do justice to the systematicity with which future expressions code temporal and epistemic information so robustly across languages. Our view, adopting a flexible principle for deriving the available interpretations, has also afforded an explanation of the system of preferences, a breach in the cross-linguistic pattern according to which statives correlate with the epistemic interpretation of modals and eventives with nonepistemic interpretations. French FUT is puzzling in this respect, as the temporal (nonepistemic) interpretation is overwhelmingly preferred with both statives and eventives.

We have also proposed that the semantics of FUT always codes future verification (direct or indirect) and that the epistemic 'interpretation' is indeed an epistemic effect that arises when the speaker has indirect evidence and the truth/falsity of $p$ or $\operatorname{RES}(p)$ is already 
settled at the time of utterance. We have shown that the epistemic effect is an inference that can be cancelled, as in (8) with the simple future, and as in the 'present ratification' use which we saw in (11)-(12) with the future anterior. In this use, we have argued, FUT represents future ratification, and, since the conjectural component is an inference that can be cancelled when the speaker has direct evidence at the time of utterance, we can propose a unified theory of FUT in which (11)-(12) are to be understood in a way parallel to (8). Such a solution could not be adopted by positing a conjectural modal in the semantics of FUT.

Finally, we have disentangled the epistemic effect (arising when the speaker has indirect evidence at $t_{u}$ ) from uncertainty at $t_{u}$. We have argued that FUT does not correlate with uncertainty (pace Dendale, 2001; Narrog, 2001), as otherwise future sentences would manifest Moore's paradox. We have explained the compatibility of FUT with a variety of epistemic adverbs via embedding. The interaction of epistemic adverbs with modals is still an under-explored field deserving a dedicated and in-depth investigation, which, going beyond theories of modal concord (e.g. Huitink, 2012), would cover the distributions observed, including the possibility of combining FUT with weak adverbs like maybe. ${ }^{20}$

\section{Address for correspondence}

Alda Mari

Institut Jean Nicod

ENS

29 rue d'Ulm

75005 Paris - France

email:alda.mari@ens.fr

${ }^{20}$ For a preliminary study, see Giannakidou and Mari (to appear-b). 


\section{REFERENCES}

Abusch, D. (2004). On the temporal composition of infinitives. In : J. Guéron and J. Lecarme (eds.), The Syntax of Time. Cambridge MA: MIT Press, pp. 1-34.

Aikhenvald, A. (2004). Evidentiality. Oxford: Oxford University Press.

Azzopardi, S., Bres, J. (2014). Quand le futur ne porte pas sur le procès qu'il actualise : futur d'énonciation et futur de découverte. Talk presented at the Chronos conference, 2014, Pisa.

Baranzini, L., de Saussure, L. (2014). Weak and strong epistemic meanings of the future tense(s) in French and Italian. Talk presented at the Chronos conference, 2014, Pisa.

Berretta, M. (1997). Sul futuro concessivo : riflessioni su un caso (dubbio) di degrammaticalizzazione. Linguistica e Filologia, 5: 7-40.

Bertinetto, P.M. (1979). Alcune ipotesi sul nostro futuro (con alcune osservazioni su potere e dovere), Rivista di Grammatica Generativa, 4: 77-138.

Bonami, O. and Godard, G. (2008). Lexical semantics and pragmatics of evaluative adverbs. In: L. McNally and C. Kennedy (eds.), Adverbs and Adjectives: Syntax, Semantics and Discourse. Oxford: Oxford University Press, pp. 274-304.

Boogaart, R. and Trnavac, R. (2011). Imperfective aspect and epistemic modality. In: A. Patard and F. Brisard (eds.), Cognitive Approaches to Tense, Aspect and Epistemic Modality. Amsterdam: John Benjamins, pp. 217-248.

Broekhuis, H. and Verkuyl, H. (2013). Binary tense and modality. Natural Language and Linguistic Theory, 32.3: 973-1009.

Caudal, P. (2012). Relations entre temps, aspect, modalité et évidentialité dans le système du français. Langue Française, 1.173: 115-129.

Celle, A. (2004). The French future tense and English will as markers of epistemic modality. 
Languages in Contrast, 5.2: 181-218.

Chevalier, J-C. (1978). Grammaire Larousse du Français Contemporain. Paris: Larousse.

Condoravdi, C. (2002). Temporal interpretation for modals. Modals for the present and modals for the past. In: D. I. Beaver, L. D. Casillas Martínez, B. Z. Clark and S. Kaufmann (eds.), The Construction of Meaning. Stanford: CSLI, pp. 59-87.

Copley, B. (2002). The Semantics of the Future. PhD Thesis, MIT.

Dalrymple, M., Kanazawa, M., Kim, Y., Mchombo, S. and Peter, S. (1998). Reciprocal expressions and the concept of reciprocity. Linguistics and Philosophy, 21: 159-210.

Damourette, J. and Pichon, E. (1911-1930). Des Mots à la Pensée: Essai de Grammaire de la Langue Française. Paris: Larousse.

Dendale, P. (2001). Le futur conjectural versus devoir épistémique: différences de valeur et restrictions d'emploi. Le Français Moderne, 69.1: 1-20.

Enç, M. (1996). Tense and modality. In: S. Lappin (ed.), Handbook of Contemporary Semantic Theory. Oxford: Blackwell, pp. 345-358.

Ernst, T. (2009). Speaker oriented adverbs. Natural Language and Linguistic Theory, 27: 497-544.

Faller, M. (2002). Semantics and Pragmatics of Evidentials in Cuzco Quechua. PhD Thesis, Stanford University.

von Fintel, K. and Gillies, A. (2010). Must...stay...strong!. Natural Language Semantics, 18: $351-383$

Giannakidou, A. and Mari, A. (2012). The future of Greek and Italian: an epistemic analysis. In: E. Chemla, V. Homer and G. Winterstein (eds.), Proceedings of conference 'Sinn und Bedeutung 17', Paris, September 2012. Online publication in the Semantics Archive, pp. 255-270. 
Giannakidou, A. and Mari, A. (2013). A two dimensional analysis of the future: modal adverbs and speaker's bias. In: M. Aloni, M. Franke and F. Roelofsen (eds.), Proceedings of the 19th Amsterdam Colloquium, Amsterdam, December 2013. Amsterdam: ILLC Publications, pp.115-122.

Giannakidou, A., and Mari, A. (to appear-a). Biased modality and epistemic weakness with the future and 'must': non veridicality, partial knowledge. In: J. Blaszack, A. Giannakidou, D. Klimek-Jankowska and K. Mygdalski (eds.), Tense, Mood, and Modality: New Perspectives on Old Questions. Chicago: University of Chicago Press.

Giannakidou, A. and Mari, A. (to appear-b). La dimension évaluative du futur: le rôle des adverbes. In: L. Baranzini, and L. de Saussure (eds.), Le Futur dans les Langues Romanes. Berne: Peter Lang AG.

Gosselin, L. (1996). Sémantique de la Temporalité en français. Champs linguistiques. Bruxelles: De Boeck.

de Haan, F. (1999). Evidentiality and epistemic modality: setting boundaries. Southwest Journal of Linguistics, 18: 83-101.

de Haan, F. (2001). The relation between modality and evidentiality. In: R. Müller and M. Reis (eds.), Modalität und Modalverben im Deutschen. Hamburg: Buske, pp. 201-216.

Huitink, J. (2012). Modal concord. A case study in Dutch. Journal of Semantics, 29.3: 403437.

Karttunen, L. (1972). Possible and must. In: J.P. Kimball (ed.), Syntax and Semantics Vol 1. New York: Academic Press, pp. 1-20.

Kaufmann, S. (2005). Conditional truth and future reference. Journal of Semantics, 22.3: 231280

Kevers, L. (2011). Accès Sémantique aux Bases de Données Documentaires. PhD, Université de Louvain-la-Neuve. 
Kissine, M. (2008). From predictions to promises. Pragmatics and Cognition, 16: 169- 189.

Klein, H-W. (1980). Es hat geklingelt; das weird der Briefträger sein. Der Fremdssprachliche Unterricht, 14: 140-143.

Kratzer, A. (1981). The notional category of modality. In: H. J. Eikmeyer and H. Rieser (eds.), Words, Worlds, and Contexts. New Approaches in Word Semantics. Berlin: de Gruyter, pp. $38-74$.

Lasersohn, P. (2005). Context dependence, disagreement, and predicates of personal taste. Linguistics and Philosophy, 28.6: 643-686.

Lee, J. (2012). Temporal constraints on the meaning of evidentiality. Natural Language Semantics, 21: 1-41.

Maingueneau, D. (1981). Approche de l'Enonciation en Linguistique Française. Paris: Hachette Université.

Malchukov, A. (2009). Incompatible categories: resolving the <present perfective paradox>. In: L. Hogeweg, H. de Hoop and A. Malchukov (eds), Cross-linguistic Semantics of Tense, Aspect, and Modality. Amsterdam/Philadelphia: John Benjamins, pp. 13-33.

Mari, A. (2009). Disambiguating the Italian future. In: N. Calzolari and A. Rumshiski (eds.), Proceedings of the conference Generative Approaches to the Lexicon GL2009, Pisa, September 2009. Pisa: Edizioni del Centro Nazionale di Ricerca, pp. 209-216.

Mari, A. (2014). Each other, asymmetry and reasonable futures. Journal of Semantics, 31.2: 209-261.

Mari, A. (2015). Modalités et Temps. Des Modèles aux Données. Berne: Peter Lang AG.

Mayol, L., Castroviejo, E. (2013). (Non)integrated evaluative adverbs in questions: A crossRomance study. Language, 89.2: 195-230.

Mithun, M. (1986). Evidential diachrony in Northern Iroquoian. In: W. Chafe and J. Nichols, (eds.), Evidentiality: The Linguistic Coding of Epistemology. Norwood, New Jersey: Ablex, pp. 89-112. 
Morency, P. (2010). Enrichissement épistémique du futur. Cahiers Chronos, 21: 197-214.

Mortelmans, T. (2000). On the 'evidential' nature of the 'epistemic' use of the German modals müssen and sollen. In: J. van der Auwera and P. Dendale (eds.), Modal Verbs in Germanic and Romance Languages. Belgian Journal of Linguistics, 14: 131-148.

Nuyts, J. (2001). Epistemic Modality, Language, and Conceptualization: A CognitivePragmatic Perspective. Amsterdam: John Benjamins.

Narrog, H. (2012). Modality, Subjectivity, and Semantic Change. Oxford: Oxford University Press.

Palmer, F.R. (1986). Mood and Modality. Cambridge: Cambridge University Press.

Pietrandrea, P. (2005). Epistemic Modality: Functional Properties and the Italian System. Amsterdam: John Benjamin.

Prior, A. (1957). Time and Modality. Oxford: Oxford University Press.

Riegel, M., Pellat, J-C. and Rioul, R. (1994). Grammaire Méthodique du Français. Paris: Presses Universitaires de France.

Rocci, A. (2000). L'interprétation épistémique du futur en italien et en français: une analyse procédurale. Cahiers de Linguistique Française, 22: 241-274.

Rossari, C., Ricci, C. and Siminiciuc, E. (2014). Interfaces between lexical meaning, rhetorical values and commitment: The case of the future in French, Italian and Romanian. Talk presented at the Chronos conference, 2014, Pisa.

de Saussure, L. and Morency, P. (2011). A cognitive-pragmatic view of the French epistemic future. Journal of French Language Studies, 22: 207-223.

Schrott, A. (1997). Futurität im Franzözischen der Gegenwart. Semantik und Pragmatik der Tempora der Zukunft. Tübingen: Gunter Narr.

Smirnova, A. (2013). Evidentiality in Bulgarian: temporality, epistemic modality, and information source. Journal of Semantics, 30.4: 479-532. 
Sten, H. (1954). Devoir + infinitif. Le Français Moderne, 22: 263-265.

Sthioul, B. (2007). Informations conceptuelle et procédurale: la piste beauzéenne. In: L. de Saussure, J. Moeschler and G. Puskas (eds.), Information Temporelle, Procédures et Ordre Discursif. Amsterdam/New York: Rodopi, pp. 105-121.

Squartini, M. (2012). Evidentiality in interaction: the concessive use of the Italian future between grammar and discourse. Journal of Pragmatics, 44: 2116-2128.

Sueur, J-P. (1979). Analyse sémantique des verbes 'devoir' et 'pouvoir'. Le Français Moderne, 2: 97-119.

Sweetser, E. (1990). From Etymology to Pragmatics: Metaphorical and Cultural Aspects of Semantic Structure. Cambridge: Cambridge University Press.

Tasmowski, L. and Dendale, P. (1998). Must/will and doit/futur simple as epistemic modal markers. Semantic value and restrictions of use. In: J. E. van der Auwera (ed.), English as a Human Language. To honour Louis Goossens. Munich: Lincom Europa, pp. 325336.

Thomason, R. (1984). Combination of tense and modality. In: D. Gabbay and F. Guenthner (eds), Handbook of Philosophical Logic: Extensions of Classical Logic. Dordrecht: Reidel, pp. 135-165.

Vet, C. (2007). The descriptive inadequacy of Reichenbach's tense system: A new proposal. In: L. de Saussure, J. Moeschler and G. Puskas (eds.), Tense, Mood and Aspect. Theoretical and Descriptive Issues. Cahiers Chronos, 17: 7-26.

Wagner, R.L. and Pinchon, J. (1991). Grammaire du Français Classique et Moderne. Paris: Hachette.

Willett, T. (1988). A cross-linguistic survey of the grammaticization of evidentiality. Studies in Language, 12: 51-97.

Wilmet, M. (1976). Etudes de Morpho-syntaxe Verbale. Paris: Klincksieck. 